University of Nebraska - Lincoln

DigitalCommons@University of Nebraska - Lincoln

Faculty Publications, Department of Psychology

Psychology, Department of

$2-2008$

Does gender moderate associations among impulsivity and health-risk behaviors?

\author{
Scott F. Stoltenberg \\ University of Nebraska-Lincoln, sstoltenberg2@unl.edu \\ Brian D. Batien \\ Black Hills State University \\ Denis G. Birgenheir \\ University of Wyoming
}

Follow this and additional works at: https://digitalcommons.unl.edu/psychfacpub

Part of the Psychiatry and Psychology Commons

Stoltenberg, Scott F.; Batien, Brian D.; and Birgenheir, Denis G., "Does gender moderate associations among impulsivity and health-risk behaviors?" (2008). Faculty Publications, Department of Psychology. 378.

https://digitalcommons.unl.edu/psychfacpub/378

This Article is brought to you for free and open access by the Psychology, Department of at DigitalCommons@University of Nebraska - Lincoln. It has been accepted for inclusion in Faculty Publications, Department of Psychology by an authorized administrator of DigitalCommons@University of Nebraska - Lincoln. 
Published in Addictive Behaviors 33:2 (February 2008), pp. 252-265; doi: 10.1016/j.addbeh.2007.09.004

Copyright (c) 2007 Elsevier Ltd. Used by permission.

http://www.sciencedirect.com/science/journal/03064603

Published online September 10, 2007.

\title{
Does gender moderate associations among impulsivity and health-risk behaviors?
}

\author{
Scott F. Stoltenberg, ${ }^{1}$ Bryan D. Batien, ${ }^{1}$ and Denis G. Birgenheir ${ }^{1,2}$ \\ ${ }^{1}$ Black Hills State University, Department of Psychology, \\ 1200 University Street, Unit 9129, Spearfish, SD 57799-9129, USA \\ ${ }^{2}$ University of Wyoming, Department of Psychology, \\ 1000 E. University Ave. Laramie, WY 82071, USA \\ Corresponding author - S. F. Stoltenberg
}

\begin{abstract}
The present study explores the relations among gender, impulsivity and three health-risk behaviors relevant to young adults (tobacco use, alcohol problems and gambling problems) in a sample of 197 college-age individuals. We sought to determine whether impulsivity is associated with health-risk behaviors in the same ways for men and women. For tobacco use and gambling problems, men were at higher risk than women, and impulsivity was not significantly associated with higher risk. Higher levels of motor impulsivity in men accounted for a significant amount of the gender difference in risk for alcohol problems. That is, impulsivity as measured by the Barratt Impulsiveness Scale (version 11), mediated the association between gender and risk for alcohol problems. For impulsivity as measured by Stop Signal Reaction Time (i.e. response inhibition), gender moderated the association between impulsivity and alcohol problems. Specifically, lower levels of impulsivity were associated with greater risk for alcohol problems in both men and women, but the effect was stronger in men. We speculate that this seemingly paradoxical result might be the result of coping drinking to deal with negative affect associated with behavioral overcontrol. These findings suggest that prevention efforts might well focus on identifying individuals at high risk for alcohol problems, especially males, by assessing response inhibition.
\end{abstract}

Keywords: impulsivity, alcohol use disorder, tobacco use, gambling, gender

\section{Introduction}

Young adults are at high risk for addiction to nicotine, alcohol and gambling. Although most can be exposed to tobacco, alcohol and gambling without incurring significant problems, some individuals develop addictions. 
Male gender is another risk factor for engaging in and developing problems from health-risk behaviors. This is especially true for alcohol use and for gambling, but not for tobacco use. Men tend to have more risk factors and fewer protective factors than women for alcohol use and problems (Nolen-Hoeksema \& Hilt, 2006). Male college students are relatively more likely than are female college students to have drunk in the last month, and they are much more likely to drink heavily (O'Malley \& Johnston, 2002). Consistent with that trend, men are more likely than women to have drinking problems (Wilsnack et al., 2000). Rates of lifetime gambling are comparable in for men and women, but rates of problem and pathological gambling are higher for men than for women (Engwall et al., 2004; Slutske et al., 2003). Men and women pathological gamblers report different motivations for gambling (Ledgerwood \& Petry, 2006). Men and women have comparable rates of tobacco use for college students (Patterson, et al., 2004) and adults in general (Centers for Disease Control, 2006). However, men are more likely than women to transition from occasional smokers to regular smokers over time (Wetter et al., 2004). It seems then that there are gender differences in the motivations for, the rates of and the consequences of health-risk behaviors such as drinking, gambling and tobacco use.

Impulsivity, variously expressed as a lack of planning, too quick responding, inability to delay gratification and poor inhibitory control, is also risk factor for engaging in health-risk behaviors and for developing problems as a result. Impulsivity has been associated with increased risk for engaging in health-risk behaviors, including tobacco use (Baker et al., 2004; Billieux et al., 2007), alcohol abuse (Gerald \& Higley, 2002), and gambling (Slutske et al., 2005). It appears that impulsivity is a general factor that increases risks for engaging in health-risk behaviors, without specifically predisposing an individual toward any particular health-risk behavior. There is strong evidence that impulsivity is to be an important trait-marker for a common pathway to addictive behaviors (Chambers \& Potenza, 2003). It is likely that individual differences in the predisposition to engage in specific health-risk behaviors are the product of an individual's unique genes and environmental exposure (Caspi \& Moffitt, 2006). Furthermore, young adults are at relatively high risk for gambling problems and other health-risk behaviors because of brain maturation events relevant to behavioral control (Chambers \& Potenza, 2003). So, individual level traits, such as impulsivity and gender, are important risk factors for engaging in health-risk behaviors for young adults although the nature of these relations is not fully understood.

While there is much agreement that deficient self-control is a risk factor for behavioral problems, there is less agreement on the underlying nature of impulsivity. It is generally understood that impulsivity is not a unitary construct; rather it is likely composed of multiple varieties that may be independent. Researchers from different areas such as personality (Carver, 2005), developmental psychopathology (Nigg, 2000) and behavioral pharmacology (Evenden, 1999) have described theories of impulsivity that include two, eight and ten varieties of impulsivity, respectively. There is substantial overlap in these taxonomies and the distinction between automatic versus effortful processes appears to be especially relevant in all.

There do not appear to be consistent differences between men and women on impulsivity (Feingold, 1994; Patton et al., 1995; Reynolds et al., 2006). Gender may moderate the associations between impulsivity and some health-risk behaviors but not others. For example, one study found that high impulsivity was associated with increased alcohol use in both men and women, but only in women was high impulsivity associated with increased nicotine use (Waldeck \& Miller, 1997). A more recent study also found impulsivity to be associated with smoking in women, but not in men (Grano et al., 2007). Therefore, while gender is an important factor for understanding the propensity to engage in health-risk behavior, the relationship does not appear to be simple. 
To better understand the relations among gender, impulsivity and health-risk behaviors we sought to characterize a college-age population on these constructs in a cross-sectional study. In recognition that impulsivity is not unidimensional (Reynolds et al., 2006), we assessed it using two well-validated measures of impulsivity: the Barratt Impulsiveness Scale (BIS-11; self-report) and the Stop Task (behavioral). We hypothesized that higher levels of impulsivity would be associated with increased levels of health-risk behaviors (i.e. tobacco use, drinking problems, and gambling problems) but that the expression of these relations would be different for men and women.

\section{Methods}

\subsection{Participants}

For the present study, participants were college-age individuals $(N=200 ; 73$ men/124 women; three did not report gender and were not included in the study sample) attending a small midwestern university. Based on self-reports, the sample was composed of the following distribution of ethnicities: 95.9\% $(n=189)$ Caucasian/White; 2.5\% $(n=5)$ American Indian/Alaska Native; $0.5 \%(n=1)$ Hispanic/Latino; and 1.0\% $(n=2)$ Multiracial. This distribution of ethnicities is consistent with the local demographics. The mean age of participants was 22.67 years of age (SD $=5.69$, range $=18-47)$. Participants were recruited using flyers and in-class presentations. Participants received $\$ 5$ for approximately one hour of their time. The study protocol was approved by the Institutional Review Board and all participants provided informed consent.

\subsection{Procedure}

Each participant completed a self-report questionnaire (that included the instruments listed below), two computerized tasks (only Stop Task results will be reported here), and donated a cheek cell sample for later genetic analysis. Results of the genetic analyses and of the other assessments will be reported elsewhere.

\subsection{Measures}

\subsubsection{South Oaks Gambling Screen (Lesieur E Blume, 1987)}

The South Oaks Gambling Screen (SOGS) assesses possible pathological gambling problems. While the SOGS cannot be used to diagnose Pathological Gambling, items on the SOGS are correlated with DSM-IV symptoms for Pathological Gambling $(r=.80)$. The usual DSM-IV cutoff of five symptoms identifies fewer pathological gamblers than does the cutoff SOGS score of 5 (Cox et al., 2004; Stinchfield, 2002). Higher scores on the SOGS denote more gambling problems. Internal consistency of the SOGS is high (Cronbach's $\alpha=.97)$ and the test-retest reliability is acceptable $(r=.71)$ for classifying pathological gamblers (Lesieur \& Blume, 1987).

\subsubsection{Barratt Impulsiveness Scale, Version 11 (Patton et al., 1995)}

The Barratt Impulsiveness Scale, Version 11 (BIS-11) is a widely used 30-item questionnaire that assesses levels of impulsivity. Scores on the BIS-11 can be broken down into three subscales: Motor impulsiveness (e.g. "I do things without thinking"), Nonplanning impulsiveness (e.g. "I plan for the future" - reversed scored), and Attentional impulsiveness (e.g. "I am a careful thinker" - reversed 
scored). Higher scores on the BIS-11 denote higher levels of impulsivity. Internal consistency of BIS11 Total score for college students is acceptable (Cronbach's $\alpha=.82)$ (Patton et al., 1995).

\subsubsection{Michigan Alcoholism Screening Test (Selzer, 1971)}

The Michigan Alcoholism Screening Test (MAST) is a 23-item questionnaire used to assess alcohol-related problems such as negative social consequences (e.g. "Have you ever lost friends because of your drinking?"), alcohol dependence (e.g. "Do you drink before noon fairly often?"), and general loss of control over drinking (e.g. "Can you stop drinking without difficulty after one or two drinks?"). Each item is scored either 0 or 1 and summed for the total score. Total MAST scores are interpreted as: 0-2 "no apparent problem", 3-5 "early middle or problem drinker", 6 or more "problem drinker". Internal consistency of the MAST is acceptable (Cronbach's $\alpha>.80$ ) as is test-retest reliability $(r>$.80) (Selzer, 2000).

\subsubsection{Tobacco use}

Two items were used to determine tobacco use status. Participants providing an affirmative response to either "Do you regularly smoke cigarettes?" or "Do you regularly chew tobacco?" were coded as "Tobacco Users".

\subsubsection{Stop Task (Logan et al., 1997)}

The Stop Task is a computerized task used to assess levels of impulsivity (i.e. response inhibition). This task consists of pressing the " $\mathrm{M}$ " key on the keyboard when an " $\mathrm{X}$ " appears on the screen or pressing the "Enter" key when an "O" appears. Go Reaction time (GoRT) is an index of speed of responding to these "Go" Trials. During this task, a tone (the stop signal) occurs on $25 \%$ of the trials and signals to the participant that they should not press a key on that trial. The tone initially occurs $250 \mathrm{~ms}$ (the stop delay) after the presentation of the visual stimulus, and is dynamically adjusted based on the response by the participant to either make it harder or easier to withhold responding. Specifically, the stop delay was increased by $50 \mathrm{~ms}$ following trials in which the participant inhibited responding. The stop delay was decreased by $50 \mathrm{~ms}$ following trials in which the participant was unable to inhibit responding. These dynamic stop delay adjustments result in response inhibition on approximately $50 \%$ of stop trials. The stop signal reaction time (SSRT) is an index of response inhibition calculated by subtracting the mean stop delay from the mean GoRT. Higher SSRTs are interpreted as indicating higher levels of impulsivity. That is, higher levels of SSRT indicate a slower "stopping system" (i.e. less response inhibition), which is interpreted as higher levels of impulsivity. Split-half reliabilities for individuals between ages 18-59 is good $(r \geq$.90) (Williams et al., 1999). Children with Attention-deficit/Hyperactivity Disorder have significantly longer SSRTs than children without the disorder, suggesting that those with ADHD have deficient inhibitory control (Schachar et al., 2000). Individuals with higher impulsivity according to self-reports have longer SSRTs (Logan et al., 1997).

\subsection{Analysis}

Because tobacco use, number of drinking problems and number of gambling problems were not normally distributed we used non-parametric tests (i.e. chi-square and Mann-Whitney $U$ test) to examine gender differences. We used independent sample $t$ tests to compare mean performance on Stop Task and on mean BIS-11 scores for groups defined by gender and problem behavior (i.e. tobacco use, drinking problems and gambling problems). Individuals were assigned 
scores $(1=$ yes, $0=$ no) for three variables to represent whether (1) they indicated using tobacco, (2) they indicated having more than two alcohol problems on the MAST, and (3) they indicated having any gambling problems. These scores were used as the dichotomous outcome variables in separate logistic regressions to test whether gender moderated the influence of impulsivity on reported tobacco use, alcohol and gambling problems. Significance of the "gender $\times$ impulsivity" interaction term would be evidence for a moderation effect (Frazier et al., 2004). To avoid interpretation difficulties that could be due to multicolinearity among variables, we decided to test only the Total score of the BIS-11 and Stop Signal Reaction time (Cohen et al, 2003). To prepare the impulsivity measures for the logistic regressions we removed outliers and transformed scores into z-scores. Gender was dummy coded, men $=0$ and women $=1$ and interaction terms were created as the product between gender and the z-score of the impulsivity measure (Cohen et al., 2003). For each of the logistic regressions gender and impulsivity (either BIS-11 Total or Stop Signal Reaction Time) were entered at Step 1. At Step 2, gender, impulsivity and the gender $\times$ impulsivity interaction term were entered. To assess the effect of including the interaction term in the model, we performed a likelihood ratio test $(G=2 *(\log$-likelihood model 1 - log-likelihood model 2$)$ with one degree of freedom).

\section{Results}

\subsection{Overall descriptive statistics}

Of the 124 women participants responding to both tobacco questions, 11.3\% (14/124) reported using tobacco. Of the 73 men participants responding to both items, 21.9\% (16/73) reported using tobacco. A higher proportion of men than of women reported using tobacco $\left(\chi^{2}=4.02, d f=1\right.$, $p=.045)$.

Score distributions for men and women on the MAST were statistically different (Mann-Whitney $U=3327.5, p=.002)$. Table 1 presents the percentages of men and women in three MAST scoring categories that represent levels of drinking problems. Men were 1.5 times more likely than were women to be classified as having some drinking problems (i.e. MAST scores $>2$ ). Nearly $55 \%$ of men and nearly $38 \%$ of women were classified as having some drinking problems.

Score distributions for men and women on the SOGS were statistically different (Mann-Whitney $U=2291.0, p=.000$ ). Table 1 presents the percentages of men and women in three SOGS scoring categories that represent levels of gambling problems. Men were 3.1 times more likely than were women to be classified as having any gambling problem (i.e. SOGS score $>0$ ).

Table 1 presents the means and standard deviations for measures of impulsivity (BIS-11, Stop Task). The mean score for the total BIS-11 and for each of the three subscales (attentional, nonplanning, motor) was significantly higher for men than for women $(p<.003)$. There was no difference between men and women on mean Go Trial Accuracy, speed of responding for Go Trials (GoRT), or mean Stop Signal Reaction Time (SSRT).

\subsection{Tobacco use, gender and impulsivity}

The results of the regression analyses on tobacco use are summarized in Table 2. For impulsivity as measured by the BIS-11 Total score, at Step 1, gender and BIS-11 Total score were entered. This model accounted for $4.2 \%$ of the variance (Naglekerke's $R^{2}$ ) in tobacco use. In Step 2, the gender $\times$ impulsivity interaction was added. This model accounted for a $0.2 \%$ increment in variance 
Table 1. Participant characteristics for main outcomes

\begin{tabular}{|c|c|c|c|}
\hline Measure & & Men & Women \\
\hline \multirow[t]{4}{*}{ MAST } & Score & $N=73$ & $N=124$ \\
\hline & $0-2^{\mathrm{a}}$ & 45.2 & 62.1 \\
\hline & $3-5^{b}$ & 28.8 & 25.8 \\
\hline & $6-14^{c}$ & 26.0 & 12.1 \\
\hline \multirow[t]{4}{*}{ SOGS } & Score & $N=73$ & $N=124$ \\
\hline & $0^{\mathrm{d}}$ & 32.9 & 78.2 \\
\hline & $1-4^{\mathrm{e}}$ & 56.2 & 21.0 \\
\hline & $5+{ }^{f}$ & 11.0 & 0.8 \\
\hline \multirow[t]{5}{*}{ BIS-11 } & Subscale $\left(N_{\text {men }^{\prime}}, N_{\text {women }}\right)$ & & \\
\hline & Total $(72,122)$ & $66.33(9.31)$ & $60.66(9.85)^{\star *}$ \\
\hline & Attentional $(70,122)$ & $18.26(4.51)$ & $16.78(3.63) * *$ \\
\hline & Non Planning $(73,124)$ & $24.53(4.64)$ & $22.77(4.35) *$ \\
\hline & Motor $(73,123)$ & $23.53(3.72)$ & $21.61(3.76) * * *$ \\
\hline \multirow[t]{4}{*}{ Stop Task } & Measure $\left(N_{\text {men }}, N_{\text {women }}\right)$ & & \\
\hline & Go Trial Accuracy $(70,120)$ & $.96(.03)$ & $.97(.03)$ \\
\hline & Go RT $(73,124)$ & $468.66(100.15)$ & $496.28(99.64)$ \\
\hline & SSRT $(64,108)$ & $201.69(56.47)$ & $193.86(63.15)$ \\
\hline
\end{tabular}

Percent of participants in scoring categories of the Michigan Alcoholism Screening Test (MAST) and the South Oaks Gambling Screen (SOGS). Means (standard deviations) of impulsivity measures for men and women. The total score and the subscale scores are given for the Barratt Impulsiveness Scale version 11, as are three outcomes from the Stop Task.

Different sample sizes across impulsivity measures reflect removal of outliers. Data are presented without respect to health-risk behavior status. Go RT = Go Trial Reaction Time, SSRT $=$ Stop Signal Reaction Time.

${ }^{*} p=.05 ;{ }^{* *} p=.01 ; * * * p=.001$

${ }^{a}$ No apparent problem with drinking.

${ }^{\mathrm{b}}$ Early or middle problem drinker.

${ }^{c}$ Problem drinker.

${ }^{\mathrm{d}}$ No problem with gambling.

e Some problems with gambling.

${ }^{\mathrm{f}}$ Probable pathological gambler.

explained $\left(R^{2}=4.4 \%\right)$. The likelihood ratio statistic indicated that the addition of the interaction term did not account for more variance in tobacco use than the model in Step 1; G (1) $=0.22, p=.64$. The effect of gender was significant in the initial model $(p=.05)$ with females being less likely to use tobacco (odds ratio $=0.43$ ). For impulsivity as measured by Stop Signal Reaction time, at Step 1, gender and SSRT were entered. This model accounted for $5.9 \%$ of the variance in tobacco use. In Step 2, the gender $\times$ impulsivity interaction was added. This model accounted for no change in variance explained $\left(R^{2}=5.9 \%\right)$. The likelihood ratio statistic indicated that the addition of the interaction term did not account for more variance in tobacco use than the model in Step $1 ; G(1)=0.03, p=.87$. The effect of gender was significant in the initial model $(p=.02)$ with females being less likely to use tobacco (odds ratio $=0.36$ ).

\subsection{Alcohol problems, gender and impulsivity}

The results of the regression analyses on alcohol problems are summarized in Table 3. For impulsivity as measured by the BIS-11 Total score, at Step 1, gender and BIS-11 Total score were 
Table 2. Logistic regression analyses for tobacco use

\begin{tabular}{lcccc}
\hline Variable & $B$ & SE B & $\beta$ & $p$ \\
\hline Barratt Impulsiveness Scale Total Score (BIST) & & & \\
Step 1 & & & & \\
$\quad$ Gender & -0.85 & 0.43 & -1.99 & .05 \\
BIST & 0.05 & 0.21 & 0.24 & .81 \\
Step 2 & & & & \\
$\quad$ Gender & -0.83 & 0.44 & -1.90 & .06 \\
BIST & 0.15 & 0.30 & 0.50 & .62 \\
Gender $\times$ BIST & -0.20 & 0.43 & -0.47 & .64 \\
& & & & \\
Stop Signal Reaction Time (SSRT) & & & & \\
Step 1 & -1.02 & 0.45 & -2.27 & .02 \\
Gender & -0.18 & 0.24 & -0.74 & .46 \\
SSRT & & & & \\
Step 2 & -1.01 & 0.45 & -2.24 & .03 \\
$\quad$ Gender & -0.30 & 0.76 & -0.39 & .70 \\
SSRT & 0.08 & 0.48 & 0.17 & .87 \\
Gender $\times$ SSRT &
\end{tabular}

For BIS: $N=194$; Step 1 Log-Likelihood $=-79.50$; Step 2 Log-Likelihood $=-79.39 ; G=(d f=1) 0.22, p=.64$. For SSRT: $N=172$; Step 1 Log-Likelihood $=-66.66$; Step 2 Log-Likelihood $=-66.65 ; G=(d f=1) 0.03, p=.87$.

Table 3. Logistic regression analyses for alcohol problems

\begin{tabular}{|c|c|c|c|c|}
\hline Variable & $B$ & SE $B$ & $\beta$ & $p$ \\
\hline \multicolumn{5}{|c|}{ Barratt Impulsiveness Scale Total Score (BIST) } \\
\hline \multicolumn{5}{|c|}{ Step 1} \\
\hline Gender & -0.44 & 0.32 & -1.38 & .17 \\
\hline BIST & 0.45 & 0.16 & 2.80 & .005 \\
\hline \multicolumn{5}{|l|}{ Step 2} \\
\hline Gender & -0.50 & 0.32 & -1.55 & .12 \\
\hline BIST & 0.22 & 0.25 & 0.86 & .39 \\
\hline Gender $\times$ BIST & 0.38 & 0.33 & 1.16 & .25 \\
\hline \multicolumn{5}{|c|}{ Stop Signal Reaction Time (SSRT) } \\
\hline \multicolumn{5}{|c|}{ Step 1} \\
\hline Gender & -0.66 & 0.32 & -2.04 & .04 \\
\hline SSRT & 0.15 & 0.16 & 0.34 & .36 \\
\hline \multicolumn{5}{|l|}{ Step 2} \\
\hline Gender & -0.69 & 0.33 & -2.09 & .04 \\
\hline SSRT & -1.33 & 0.61 & -2.19 & .03 \\
\hline Gender $\times$ SSRT & 0.89 & 0.35 & 2.55 & .01 \\
\hline
\end{tabular}


Table 4. Testing whether impulsivity mediates the gender effect on alcohol problems

\begin{tabular}{lcccc}
\hline Testing steps in mediation model & $B$ & SE $B$ & $\beta$ & $p$ \\
\hline Step 1 & & & & \\
$\quad$ Outcome: AlcProb & -0.69 & .30 & -2.29 & .02 \\
$\quad$ Predictor: Gender & & & & \\
Step 2 & & & & \\
$\quad$ Outcome: BIST & -0.58 & .14 & -4.09 & .000 \\
$\quad$ Predictor: Gender & & & & \\
Step 3 & 0.45 & .16 & 2.80 & .005 \\
$\quad$ Outcome: AlcProb & -0.44 & .32 & -1.38 & .17 \\
$\quad$ Mediator: BIST & & & \\
Predictor: Gender &
\end{tabular}

AlcProb = Alcohol Problem status (i.e. MAST score > 2); BIST = Barratt Impulsiveness Scale Total score. Gender was dummy coded $0=$ Men, $1=$ Women. Testing Steps 1 and 3 used logistic regression and Testing Step 2 used linear regression.

entered. This model accounted for $8.8 \%$ of the variance (Naglekerke's $R^{2}$ ) in tobacco use. In Step 2 , the gender $\times$ impulsivity interaction was added. This model accounted for a $0.9 \%$ increment in variance explained $\left(R^{2}=9.7 \%\right)$. The likelihood ratio statistic indicated that the addition of the interaction term did not account for more variance in alcohol problems than the model in Step 1; $G$ $(1)=1.33, p=.25$. The effect of impulsivity was significant in the initial model $(p=.005)$ with an odds ratio of 1.57 (higher levels of impulsivity increase odds of having some alcohol problems). However, adding the gender $\times$ impulsivity interaction term in Step 2 eliminated the impulsivity effect.

Given that we did observe a significant difference in the MAST score distribution for men and women, we found the results of the moderation test curious. We decided therefore to test whether impulsivity mediated the association between gender and MAST score that we report above in Section 3.1. Table 4 summarizes the results of our mediation tests. In Step 1 we tested whether gender was a significant predictor of alcohol problems using logistic regression. The effect of gender was significant $(p=.02)$ and explained 3.6\% of the variance in alcohol problems. In Step 2 we tested whether gender was a significant predictor of impulsivity using an ordinary least squares regression. The effect of gender was significant $(p=.000)$ and explained $7.9 \%$ of the variance in BIS-11 Total scores. The first two mediation tests showed that gender was a predictor of both alcohol problems and BIS-11 Total scores. In the final mediation test (Step 3), we conducted a logistic regression on Alcohol problem status, first entering impulsivity, then gender. The effect of impulsivity was statistically significant $(p=.005)$ and the effect of gender was not $(p=.17)$, which is evidence that the effect of gender observed in Step 1 on alcohol problems can be explained by gender differences in impulsivity. An estimate of the proportion of the total gender effect on alcohol problems that is mediated by impulsivity is $38 \%$, so the mediation is significant, but does not appear to be complete (Frazier et al., 2004).

For impulsivity as measured by Stop Signal Reaction time, at Step 1, gender and SSRT were entered (see Table 3). This model accounted for $4.0 \%$ of the variance in alcohol problems. In Step 2, the gender $\times$ impulsivity interaction was added. This model accounted for an increment of $5.1 \%$ in variance explained $\left(R^{2}=9.1 \%\right)$. The likelihood ratio statistic indicated that the addition of the interaction term accounted for more variance in alcohol problems than the model in Step 1; G (1) = 6.88, $p=.01$. The effect of gender was significant in the initial model $(p=.02)$ and in Step $2(p=.04)$ with females being less likely to have alcohol problems (odds ratios $=0.52$ and 0.50 , respectively). In Step 2, both 


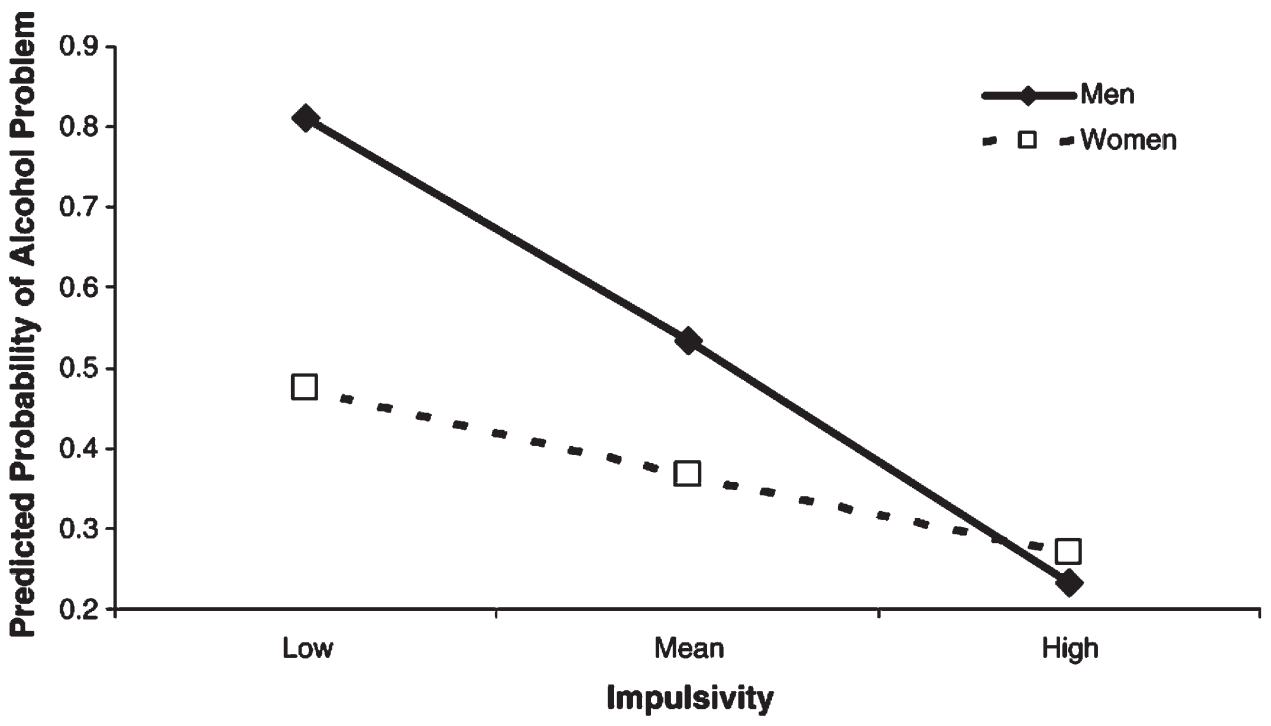

Figure 1. Plot of significant gender $\times$ impulsivity interaction. Probabilities of being assigned to the alcohol problem category are plotted for men and women at the mean, low (-1SD) and high (+ $1 \mathrm{SD})$ values of impulsivity as measured by Stop Signal Reaction Time (SSRT). Note that greater SSRTs indicate higher levels of impulsivity (i.e. it takes longer to inhibit a prepotent behavior).

the main effect for Stop Signal Reaction Time $(p=.03)$ and the gender $\times$ SSRT interaction $(p=.01)$ were statistically significant, evidence of a gender moderation. The predicted probabilities of having alcohol problems for mean, low (-1SD) and high (+ 1SD) levels of impulsivity as measured by SSRT for men and women are shown in Figure 1. Predicted logit scores for each group were obtained

Table 5. Logistic regression analysis for gambling problems

\begin{tabular}{|c|c|c|c|c|}
\hline Variable & $B$ & SE $B$ & $\beta$ & $p$ \\
\hline \multicolumn{5}{|c|}{ Barratt Impulsiveness Scale Total Score (BIST) } \\
\hline \multicolumn{5}{|c|}{ Step 1} \\
\hline Gender & -1.85 & 0.34 & -5.42 & .00 \\
\hline BIST & 0.22 & 0.17 & 1.26 & .21 \\
\hline \multicolumn{5}{|l|}{ Step 2} \\
\hline Gender & -1.85 & 0.34 & -5.38 & .00 \\
\hline BIST & 0.20 & 0.27 & 0.74 & .46 \\
\hline Gender $\times$ BIST & 0.03 & 0.35 & 0.09 & .93 \\
\hline \multicolumn{5}{|c|}{ Stop Signal Reaction Time (SSRT) } \\
\hline \multicolumn{5}{|c|}{ Step 1} \\
\hline Gender & -2.07 & 0.36 & -5.76 & .000 \\
\hline SSRT & -0.22 & 0.18 & -1.22 & .22 \\
\hline \multicolumn{5}{|l|}{ Step 2} \\
\hline Gender & -2.09 & 0.36 & -5.77 & .000 \\
\hline SSRT & 0.34 & 0.63 & 0.54 & .59 \\
\hline Gender $\times$ SSRT & 0.35 & 0.38 & -0.93 & .35 \\
\hline
\end{tabular}

For BIS: $N=194$; Step 1 Log-Likelihood $=-109.52$; Step 2 Log-Likelihood $=-109.51 ; G=(d f=1) .01, p=.93$. For SSRT: $N=172$; Step 1 Log-Likelihood $=-96.20$; Step 2 Log-Likelihood $=-95.75 ; G=(d f=1) 0.89, p=.35$. 
by multiplying the unstandardized regression coefficients with appropriate values in the regression equations for Step 2 (Frazier et al., 2004). Logit scores were then converted to probability values, which were then plotted. At mean levels of SSRT, men have a higher probability of being assigned to the alcohol problem group than women (.53 versus .37), but at the high impulsivity level, there is no apparent difference between men and women (.23 versus .27). It is at the low impulsivity level where the gender difference is the greatest with the men having a predicted probability of alcohol problems of .81 and women .47 .

\subsection{Gambling problems, gender and impulsivity}

The results of the regression analyses on gambling problems are summarized in Table 5. For impulsivity as measured by the BIS-11 Total score, at Step 1, gender and BIS-11 Total score were entered. This model accounted for $25.2 \%$ of the variance (Naglekerke's $R^{2}$ ) in gambling problems. In Step 2, the gender $\times$ impulsivity interaction was added. This model accounted for no change in variance explained $\left(R^{2}=25.2 \%\right)$. The likelihood ratio statistic indicated that the addition of the interaction term did not account for more variance in tobacco use than the model in Step 1; G $(1)=0.01, p=.93$. The effect of gender was significant in the initial model $(p=.000)$ with females being less likely to have gambling problems (odds ratio $=0.16$ ). For impulsivity as measured by Stop Signal Reaction time, at Step 1, gender and SSRT were entered. This model accounted for $27.1 \%$ of the variance in gambling problems. In Step 2, the gender $\times$ impulsivity interaction was added. This model accounted for a $0.6 \%$ increment in variance explained $\left(R^{2}=27.7 \%\right)$. The likelihood ratio statistic indicated that the addition of the interaction term did not account for more variance in gambling problems than the model in Step $1 ; G(1)=0.89, p=.35$. The effect of gender was significant in the initial model $(p=.000)$ with females being less likely to have gambling problems (odds ratio $=0.13$ ).

\section{Discussion}

The most important result of this study is that gender moderates the association between impulsivity (response inhibition) and alcohol problems. Specifically, at high levels of impulsivity there was no difference between men and women on probability of having alcohol problems. However, as levels of impulsivity decreased, the risk for alcohol problems increased for both men and women, but more dramatically in men. In addition, we found evidence that impulsivity (BIS-11 Total scores) mediates the association between gender and alcohol problems. We did not find impulsivity to be associated with tobacco use or with gambling problems. Although these findings do not fully support out initial hypothesis, they are in line with our thinking that the relations among impulsivity, gender and health-risk behaviors are not straightforward.

Our finding that higher levels of impulsivity, as measured by scores on the Barratt Impulsiveness Scale (version 11), partially accounted for the increased risk for alcohol problems experienced by males, is consistent with our initial hypothesis, but is more nuanced. Our results with the BIS-11, therefore, are largely consistent with the literature on impulsivity and alcohol use/problems such that higher impulsivity is associated with more use and/or problems (Caspi et al., 1997; Gerald and Higley, 2002; Simons et al., 2005). On further inspection of the BIS-11 results, we found that the neither the Non Planning nor the Attention subscales were associated with alcohol problem status, but the Motor impulsivity subscale was (data not shown). The items on the Motor subscale assess the ex- 
tent to which people report that they "act without thinking". So, the analyses with BIS-11 Total scores were essentially displaying the effects of the Motor subscale.

This appears to be the first report of a gender moderation of the effect of response inhibition on alcohol problems. Much of the research literature has focused on behavioral inhibition following alcohol consumption (Fillmore \& Weafer, 2004), but we were unable to find studies that specifically examined response inhibition and alcohol problems. At first, the results reported in Figure 1 seem paradoxical and they do not support our initial hypothesis that higher levels of impulsivity would be associated with greater risk for health-risk behaviors. It may be that young men who are behaviorally overcontrolled have higher levels of negative affect and may drink to cope. There is evidence that low impulsivity in males is related to coping drinking motives (Kuntsche et al., 2006) and that coping motives in males are more related to alcoholism diagnosis than are enhancement motives (Carpenter \& Hasin, 1998). In our study, we did not assess drinking motives or affect, so we are unable to test this hypothesis. However, the connection between impulsivity and motives appears to be a logical interpretation of the pattern of results we observed in Figure 1.

Our results are consistent with the view that impulsivity is not a single construct, but is composed of multiple traits and predispositions that may be independent (Evenden, 1999; Reynolds et al., 2006). Further, we provide evidence that the automatic (i.e. Motor impulsivity) and controlled (i.e. response inhibition) types of impulsivity have different relations to risk for alcohol problems (i.e. mediation versus moderation) for men and women. These data seem to fit with a recent theoretical model on adolescent drinking that details an imbalance between appetitive motivation and selfcontrol (Wiers et al., 2007). Considering gender and using both questionnaires and behavioral tasks may be necessary to assess aspects of impulsivity relevant for understanding propensity to engage in health-risk behaviors.

In order to fully understand the etiologic mechanisms for behavioral disorders such as substance abuse, and gambling, a detailed view of impulsivity's role must be achieved. Substantial empirical evidence indicates that varieties of impulsivity exist and should be considered. The present study provides additional evidence that gender should be considered when examining the influence of impulsivity on behavioral outcomes. A great deal of work remains before a complete understanding of the pathways from genes to the propensity for engaging in health-risk behaviors via impulsivity is achieved, but it is clear that gender must be considered.

In our sample, we observed gender differences in impulsivity as assessed by the BIS-11 questionnaire (mean scores for males were higher than mean scores for women), which contrasts with other studies (Feingold, 1994; Patton et al., 1995; Reynolds et al., 2006). Mean BIS-11 total scores for women in the present study were significantly lower than reported norms $(t=2.478$; $d f=242$, $p=.01)$, whereas mean scores for males in the present study were not different $(t=-0.986 ; d f=160$, n.s.) from reported norms (Patton et al., 1995). Reported rates of tobacco use in this study (11.3\% of women and $21.9 \%$ of men) were substantially lower than those reported in other college-age samples in which $29 \%$ identify themselves as current smokers with no substantial gender difference (Patterson et al., 2004). The relatively high percentage of men endorsing more than two items on the MAST $(54.8 \%)$ is likely a reflection of the high levels of alcohol use in South Dakota. In a recent survey, $72.4 \%$ of South Dakotans aged 18-25 reported drinking in the past month compared to the national average of $60.7 \%$ (Wright \& Sathe, 2006). In the same age group, $52.2 \%$ of South Dakotans reported binge drinking (five or more drinks in a drinking occasion) compared to the national average of $41.5 \%$ (Wright \& Sathe, 2006). The impulsivity and tobacco use differences observed in our sample could represent under-reporting in our study or a recruitment bias, especially for women. We are unable to determine the source of this discrepancy, but interpretations of our results, especially with respect to tobacco use, should consider this potential bias. In addition, the 
study sample is not ethnically diverse, which might affect the generalizability of the results to nonCaucasian groups. There is no obvious reason that these results would not generalize to other similar populations (young, primarily Caucasian adults). There remains much to learn regarding the relations among impulsivity, gender and health-risk behaviors, because although we studied important health-risk behaviors in a population at high risk, there are other relevant health-risk behaviors (e.g. risky sex, risky driving) and other aspects of impulsivity (e.g. boredom susceptibility) that we did not assess.

Theoretical models of the etiology of nicotine dependence, alcohol use disorders and pathological gambling should consider the gender moderation of the influence of impulsivity on these behaviors. And efforts should be undertaken to better characterize these relations and to better understand the role of impulsivity in the propensity to engage in health-risk behaviors. Efforts at preventing alcohol problems in adolescents may benefit by focusing attention on males with high levels of response inhibition (i.e. low impulsivity).

\section{Acknowledgments}

This project was made possible by Grant Number 2 P20 RR016479 from the National Center for Research Resources (NCRR), a component of the National Institutes of Health (NIH); by a Governor's 2010 Individual Research Seed Grant (SDBOR/BHSU 2010-06-01); by a Nelson Summer Research Fellowship (BDB) and by a grant by the BHSU Faculty Research Committee (SFS). The authors would like to thank Dr. Parthasarathi Nag, for statistical advice, anonymous reviewers for comments and Kelley Aline, Melissa Lehmann, Ben Roman, Jeanie Stockland and Joanna Vandever for assistance with data collection; and the volunteer participants, without whose efforts this research could not have been conducted.

\section{References}

Baker et al., 2004 T. B. Baker, T. H. Brandon and L. Chassin, Motivational influences on cigarette smoking, Annual Review of Psychology 55 (2004), pp. 463-491.

Billieux et al., 2007 J. Billieux, M. Van der Linden and G. Ceschi, Which dimensions of impulsivity are related to cigarette craving?, Addictive Behaviors 32 (6) (2007), pp. 1189-1199.

Carpenter and Hasin, $1998 \rightarrow$ K. M. Carpenter and D. Hasin, A prospective evaluation of the relationship between reasons for drinking and dsm-iv alcohol-use disorders, Addictive Behaviors 23 (1) (1998), pp. 41-46.

Carver, 2005 C. S. Carver, Impulse and constraint: Perspectives from personality psychology, convergence with theory in other areas, and potential for integration, Personality and Social Psychology Review 9 (4) (2005), pp. 312-333.

Caspi et al., 1997 A. Caspi, D. Begg, N. Dickson, H. Harrington, J. Langley and T. E. Moffitt et al., Personality differences predict health-risk behaviors in young adulthood: Evidence from a longitudinal study, Journal of Personality and Social Psychology 73 (5) (1997), pp. 1052-1063.

Caspi and Moffitt, 2006 A. Caspi and T. E Moffitt, Gene-environment interactions in psychiatry: Joining forces with neuroscience, Nature Reviews. Neuroscience 7 (7) (2006), pp. 583-590.

Centers for Disease Control, 2006 Centers for Disease Control, Tobacco use among adults-united states 2005, Morbidity and Mortality Weekly Report 55 (42) (2006), pp. 1145-1148.

Chambers and Potenza, $2003 \rightarrow$ R. A. Chambers and M. N. Potenza, Neurodevelopment, impulsivity, and adolescent gambling, Journal of Gambling Studies 19 (1) (2003), pp. 53-84.

Cohen et al., 2003 J. Cohen, P. Cohen, S. G. West and L. S. Aiken, Applied multiple regression/correlation analysis for the behavioral sciences (3rd ed. ), Lawrence Erlbaum Associates, Inc, Mahwah, NJ (2003).

Cox et al., 2004 B. J. Cox, M. W. Enns and V. Michaud, Comparisons between the south oaks gambling screen and a DSM-IV-based interview in a community survey of problem gambling, Canadian Journal of Psychiatry 49 (4) (2004), pp. 258-264. 
Engwall et al., $2004>$ D. Engwall, R. Hunter and M. Steinberg, Gambling and other risk behaviors on university campuses, Journal of American College Health 52 (6) (2004), pp. 245-255.

Evenden, 1999 J. L. Evenden, Varieties of impulsivity, Psychopharmacology (Berl) 146 (4) (1999), pp. 348-361.

Feingold, 1994 A. Feingold, Gender differences in personality: A meta-analysis, Psychological Bulletin 116 (3) (1994), pp. 429-456.

Fillmore and Weafer, $2004>$ M. T. Fillmore and J. Weafer, Alcohol impairment of behavior in men and women, Addiction 99 (10) (2004), pp. 1237-1246.

Frazier et al., $2004-$ P. A. Frazier, A. P. Tix and K. E. Barron, Testing moderator and mediator effects in counseling psychology research, Journal of Counseling Psychology 51 (1) (2004), pp. 115-134.

Gerald and Higley, 2002 M. S. Gerald and J. D. Higley, Evolutionary underpinnings of excessive alcohol consumption, Addiction 97 (4) (2002), pp. 415-425.

Grano et al., 2007 N. Grano, L. Keltikangas-Jarvinen, A. Kouvonen, M. Virtanen, M. Elovainio and J. Vahtera et al., Impulsivity as a predictor of newly diagnosed depression, Scandinavian Journal of Psychology 48 (2) (2007), pp. 173-179.

Kuntsche et al., 2006 E. Kuntsche, R. Knibbe, G. Gmel and R. Engels, Who drinks and why? A review of socio-demographic, personality, and contextual issues behind the drinking motives in young people, Addictive Behaviors $\mathbf{3 1}$ (10) (2006), pp. 1844-1857.

Ledgerwood and Petry, 2006 D. M. Ledgerwood and N. M. Petry, Psychological experience of gambling and subtypes of pathological gamblers, Psychiatry Research 144 (1) (2006), pp. 17-27.

Lesieur and Blume, 1987 H. R. Lesieur and S. B. Blume, The south oaks gambling screen (SOGS): A new instrument for the identification of pathological gamblers, American Journal of Psychiatry 144 (9) (1987), pp. 1184-1188.

Logan et al., 1997 G. D. Logan, R. Schachar and R. Tannock, Impulsivity and inhibitory control., Psychological Science 8 (1997), pp. 60-64.

Nigg, 2000 J. T. Nigg, On inhibition/disinhibition in developmental psychopathology: Views from cognitive and personality psychology and a working inhibition taxonomy, Psychological Bulletin 126 (2) (2000), pp. 220-246.

Nolen-Hoeksema and Hilt, 2006 S. Nolen-Hoeksema and L. Hilt, Possible contributors to the gender differences in alcohol use and problems, Journal of General Psychology 133 (4) (2006), pp. 357-374.

O'Malley and Johnston, 2002 P. M. O'Malley and L. D. Johnston, Epidemiology of alcohol and other drug use among American college students, Journal of Studies on Alcohol. Supplement 14 (2002), pp. 23-39.

Patterson et al., 2004 F. Patterson, C. Lerman, V. G. Kaufmann, G. A. Neuner and J. Audrain-McGovern, Cigarette smoking practices among American college students: Review and future directions, Journal of American College Health 52 (5) (2004), pp. 203-210.

Patton et al., 1995 J. H. Patton, M. S. Stanford and E. S. Barratt, Factor structure of the Barratt impulsiveness scale, Journal of Clinical Psychology 51 (6) (1995), pp. 768-774.

Reynolds et al., 2006 B. Reynolds, A. Ortengren, J. B. Richards and H. de Wit, Dimensions of impulsive behavior: Personality and behavioral measures, Personality and Individual Differences 40 (2) (2006), p. 305.

Schachar et al., $2000>$ R. Schachar, V. L. Mota, G. D. Logan, R. Tannock and P. Klim, Confirmation of an inhibitory control deficit in attention-deficit/hyperactivity disorder, Journal of Abnormal Child Psychology 28 (3) (2000), pp. 227-235.

Selzer, 1971 M. L. Selzer, The Michigan alcoholism screening test: The quest for a new diagnostic instrument, American Journal of Psychiatry 127 (12) (1971), pp. 1653-1658.

Selzer, 2000 M. L. Selzer, Michigan alcoholism screening test (MAST), Handbook of psychiatric measures, American Psychiatric Association, Washington, D. C. (2000), pp. 467-468.

Simons et al., 2005 J. S. Simons, R. M. Gaher, C. J. Correia, C. L. Hansen and M. S. Christopher, An affectivemotivational model of marijuana and alcohol problems among college students, Psychol Addictive Behaviors 19 (3) (2005), pp. 326-334.

Slutske et al., 2005 W. S. Slutske, A. Caspi, T. E. Moffitt and R. Poulton, Personality and problem gambling: A prospective study of a birth cohort of young adults, Archives of General Psychiatry 62 (7) (2003), pp. 769-775. 
Slutske et al., 2003 W. S. Slutske, K. M. Jackson and K. J. Sher, The natural history of problem gambling from age 18 to 29, Journal of Abnormal Psychology 112 (2) (2003), pp. 263-274.

Stinchfield, 2002 R. Stinchfield, Reliability, validity, and classification accuracy of the south oaks gambling screen (SOGS), Addictive Behaviors 27 (1) (2002), pp. 1-19.

Waldeck and Miller, 1997 T. L. Waldeck and L. S. Miller, Gender and impulsivity differences in licit substance use, Journal of Substance Abuse 9 (1997), pp. 269-275.

Wetter et al., 2004 D. W. Wetter, S. L. Kenford, S. K. Welsch, S. S. Smith, R. T. Fouladi and M. C. Fiore et al., Prevalence and predictors of transitions in smoking behavior among college students, Health Psychology 23 (2) (2004), pp. 168-177.

Wiers et al., 2007 R. W. Wiers, B. D. Bartholow, E. van den Wildenberg, C. Thush, R. C. Engels and K. J. Sher et al., Automatic and controlled processes and the development of addictive behaviors in adolescents: A review and a model, Pharmacology, Biochemistry \& Behavior 86 (2) (2007), pp. 263-283.

Williams et al., 1999 B. R. Williams, J. S. Ponesse, R. J. Schachar, G. D. Logan and R. Tannock, Development of inhibitory control across the life span, Developmental Psychology 35 (1) (1999), pp. 205-213.

Wilsnack et al., $2000>$ R. W. Wilsnack, N. D. Vogeltanz, S. C. Wilsnack, T. R. Harris, S. Ahlstrom and S. Bondy et al., Gender differences in alcohol consumption and adverse drinking consequences: Cross-cultural patterns, Addiction 95 (2) (2000), pp. 251-265.

Wright and Sathe, 2006 D. Wright and N. Sathe, State estimates of substance use from the 2003-2004 national surveys on drug use and health (DDHS Publication No. SMA 06-4142, NSDUH Series H-29), Substance Abuse and Mental Health Services Administration, Office of Applied Studies, Rockville, MD (2006). 